Article

\title{
Coupling of Water Activity and Colour Development of Roast Duck Skin under Forced Convection Drying
}

\author{
Yingbo Peng ${ }^{1}$, Xiuyun Guo ${ }^{2}$, Muneer Ahmed Jamali ${ }^{3}$ and Yawei Zhang ${ }^{2, *}$ \\ 1 College of Engineering, Nanjing Agricultural University, Nanjing 210095, China; ybpengnj@njau.edu.cn \\ 2 College of Food Science and Technology, National Center of Meat Quality and Safety Control, \\ Nanjing Agricultural University, Nanjing 210095, China; guoxiuyun@njau.edu.cn \\ 3 Department of Animal Products Technology, Sindh Agriculture University, Tandojam 70060, Pakistan; \\ majamali65@yahoo.com \\ * Correspondence: zhangyawei@njau.edu.cn
}

Received: 13 August 2020; Accepted: 9 September 2020; Published: 17 September 2020

\begin{abstract}
Roasting meat involves simultaneous heat and mass transfer, colour and flavour development and the formation of hazardous chemicals. The objectives of this study were to evaluate the effects of temperature and time on colour, 3,4-benzo(a)pyrene (BaP) and heterocyclic aromatic amines (HCAs) in roast duck skin during forced hot-air drying at less than $130^{\circ} \mathrm{C}$. The results showed that surface and internal temperatures of duck carcasses increased with drying time, rising to 111.9 and $83.7^{\circ} \mathrm{C}$, respectively. The curves of water activity $\left(\mathrm{a}_{\mathrm{w}}\right)$ and red index $\left(\mathrm{a}^{*}\right)$ intersected at 50 min because of the decrease in $\mathrm{a}_{\mathrm{w}}$ and the increase in $\mathrm{a}^{*}$ on the skin with drying time. The drastic decline in $\mathrm{a}_{\mathrm{w}}$ promoted colour development on the duck surface. BaP and carcinogenic HCAs were not detected in hot-air drying ducks, convincing us that the mild cooking method under forced hot-air drying could effectively reduce or eliminate the risk of certain human cancers.
\end{abstract}

Keywords: forced hot-air drying; hazardous chemicals; water activity; red index; roast duck

\section{Introduction}

Traditional cooking methods, for example, deep frying and roasting, endow meat with a good colour and flavour. The traditional roast duck, for example, Peking roast duck, is roasted with an open flame and various types of wood, such as apple wood, maple wood or spruce wood, or charcoal, or via electric oven roasting [1]. In order to predict the temperature and moisture profiles of chicken breast meat (skinless and boneless) with the dimensions of $40 \times 20 \times 70 \mathrm{~mm}$ during roasting $\left(170-230^{\circ} \mathrm{C}\right)$ on a stainless steel baking tray in a forced convection oven, a numerical 3D model of coupled transport phenomena and texture changes during the roasting of chicken breast meat in a convection oven was developed [2]. The developed model provides deep insights into the local and spatial texture changes of chicken breast meat during the roasting process. Feyissa et al. [3] developed the mathematical model of coupled heat and mass transfer during the roasting of meat in a convection oven (oven temperature of $175^{\circ} \mathrm{C}$ ). The model can be used to improve the prediction of temperature and moisture loss, and to support quality control during roasting. At high temperature $\left(150-300^{\circ} \mathrm{C}\right)$, however, hazardous chemicals, such as polycyclic aromatic hydrocarbons (PAHs) and heterocyclic aromatic amines (HCAs), can form in roasted duck. Several epidemiological studies suggested that frequent consumption of HCAs naturally generated in muscle meat during cooking was strongly associated with human carcinogenesis at multiple sites, such as breast, colon, rectum and prostate [4]. PAHs are a group of over 100 different compounds which are produced through incomplete combustion or pyrolysis of organic matter and geological processes. Among them, benzo[a] pyrene $(\mathrm{BaP})$ is carcinogenic to humans (group 1), whereas benz[a] anthracene (BaA), chrysene (Chry), benzo[k]fluoranthene (BkF) 
and benzo[b]fluoranthene $(\mathrm{BbF})$ are possibly carcinogenic to humans [5]. HCAs are a group of 20 different chemical compounds which are produced in cooked meats. HCAs which are produced during the cooking of meat are classified as amino amidazo azoarenes (AIAs) that contain the N-methyl-2aminoimidazole moiety and are proposed to form through the reaction of pyridine or pyrazines to produce the "IQ- and IQx-type" compounds [6], and amino carbolines are formed in proteins or produced directly from the pyrolysis of amino acids heated at high temperature [7], such as 2-amino-9H-pyridole (2,3-b]indole (A $\alpha \mathrm{C})$. Lin et al. [8] found that the total amount for PAHs in the skin of roasted ducks was detected at a level as high as $54.7 \mu \mathrm{g} / \mathrm{kg}$. In addition, Chung et al. [9] found high levels of PAHs (10.2 $\mu \mathrm{g} / \mathrm{kg}$ on average) in charcoal-grilled pork, and Aaslyng et al. [10] reported similar findings for beef and chicken barbecued at home. Taken together, these studies indicate, in general, a correlation between the HCA content and the surface colour of the meat, in which a darker colour was associated with higher HCA concentrations. Yao et al. [11] reported that chicken skin in deep fried and braised chicken contained $68.80 \mathrm{ng} / \mathrm{g}$ of total HCAs. In view of the potential carcinogenicity of deep fried [12], grilled or barbecued meat [13], there have been efforts since the early 1990s to develop new cooking techniques for processed meat to reduce the risk of certain human cancers [14,15].

Due to the carcinogenic properties, the maximum permitted level for $\mathrm{BaP}$ in smoked meats and smoked meat products is $2.0 \mu \mathrm{g} / \mathrm{kg}$, and the content of BaP should not exceed $1.0 \mu \mathrm{g} / \mathrm{kg}$ for processed cereal-based foods (EC, 2011) [16]. An amount of $5 \mu \mathrm{g} / \mathrm{kg}$ for BaP in grilled pork, lamb, duck and chicken was required by Chinese National Criteria (1994) [17]. Roasting meat in a forced convection oven that involves simultaneous heat and mass transfer affects the temperature and moisture distribution within the rectangular blocks of pork meat during roasting [3]. Unfortunately, however, for a whole chicken or whole duck, there is a diminished association between water activity and colour development. Therefore, the objective of the present work was to deal with alterations in the water activity and colour development of duck skin under hot-air drying at mild temperatures $\left(120-130^{\circ} \mathrm{C}\right)$ in a forced convection industrial oven. Based on this, a novel cooking technology will be developed, in place of roasting, for maintaining a favourable colour of the final product and effectively decreasing the formation of HCAs and 3,4-benzo(a)pyrene (BaP).

\section{Materials and Methods}

\subsection{Chemicals and Standards}

The HCAs standards, including 2-amino-3-methylimidazo[4,5-f]quinoline (IQ, CAS no. 76180-96-6), 2-amino-3,4-dimethylimidazo[4,5-f]quinoline (MeIQ, CAS no. 77094-11-2), 2-amino-3,4-dimethylimidazo quinoline (MeIQx, CAS no. 77500-04-0), 2-amino-3,4,8-trimethylimidazoquinoxaline (4,8-DiMeIQx, CAS no. 95896-78-9), 2-amino-3,7,8-trimethylimidazo[4,5-f] quinoxaline (7,8-DiMeIQx, CAS no. 92180-79-5), 9H-pyrido[3,4-b]indole (Norharman, CAS no. 244-63-3), 1-methyl-9H-pyrido[3,4-b]indole (Harman, CAS no. 486-84-0), 2-amino-1-methyl-6-phenylimidazo[4,5-b]pyridine (PhIP, CAS no. 105650-23-5), 3-amino-1,4-dimethyl-5H-pyrido[4,3-b]indole (TrP1, CAS no. 68808-54-8), 3-amino-1-methyl-5Hpyrido[4,3-b]indole (TrP2, CAS no. 72254-58-1), 2-amino-3-methyl-9H-pyrido[2,3-b]indole (A $\alpha \mathrm{C}$, CAS no. 26148-68-5) and 2-Amino-3-methyl-9H-pyrido[2,3-b]indole (MeA $\alpha$ C, CAS no. 68006-83-7) were purchased from Toronto Research Chemicals (Downsview, ON, Canada) and prepared by dissolving $5 \mathrm{mg}$ of each chemical in $50 \mathrm{~mL}$ of methanol. The standard BaP were purchased from Supelco (Bellefonet, PA, USA). Acetonitrile were HPLC grade and purchased from Merk (Darmstadt, Germany). Other analytical-grade chemicals were obtained from Sinopharm Chemical Reagent Co. Ltd. (Shanghai, China). Deionised water was produced using a Millipore water purification system (Millipore Co., Bedford, MA, USA).

\subsection{Sample Preparation}

Thirty frozen Cherry Valley duck carcasses (1.25-1.5 kg in wet weight) and acacia bee honey were purchased from a local supermarket in Nanjing. The ducks carcasses were removed from the refrigerator and allowed to reach room temperature before being used in the study. The duck carcasses 
were randomly divided into three groups. To investigate the effects of drying time on water activity $\left(a_{\mathrm{w}}\right)$ and surface colour, ducks were brushed with a solution of $50 \%$ bee honey (wt/wt in water, $15 \mathrm{~g} / \mathrm{kg}$ of duck) and drained at room temperature for $10 \mathrm{~min}$. Then, each group (ten ducks) was hung and dried in a forced convection oven when the working temperature inside the oven reached $130{ }^{\circ} \mathrm{C}$. The purchased roast ducks (two Peking ducks from company A and B in Beijing, one roast duck from company $C$ in Nanjing) and the prepared roast ducks in the present work were vacuum-packaged after sterilisation. Both company A duck and company B duck were traditional roast duck, and were roasted with an open flame and wood. Company $\mathrm{C}$ duck was roasted by an open gas flame.

\subsection{Oven Condition and Description of the Drying Process}

\subsubsection{Description of the Drying Process and Monitoring of the Internal Temperature}

An industrial forced convection oven (Jiaxing Expro Industrial Co., Ltd., Jiaxing, China) with drying chamber dimensions of $0.69 \times 0.93 \times 1.15 \mathrm{~m}$ was used for the drying experiments. Dry hot air was blown into the drying chamber from both sides of the oven top and circulated inside the chamber by means of a fan at high speed. The oven temperature was controlled by the oven thermostat, and remained around $130^{\circ} \mathrm{C}$ with a standard deviation of $\pm 3^{\circ} \mathrm{C}$. One thermocouple was placed on the left interior side of the oven to continuously monitor the working temperature, and the other thermocouple for monitoring the internal temperature was inserted between the sternum and pectoralis major of one duck carcass from each group. The difference between the surface temperature and internal temperature $(\delta \mathrm{T})=$ surface temperature - internal temperature. The drying process involved mild temperatures, and the following took place during drying: (a) fat transport and fat loss occurred only in the subcutaneous fat layer; (b) cracks formed on the crust layer of the skin; (c) evaporation took place on the surface. The water vapor from the surface was transported into the drying chamber and discharged out from the air exhaust on the top of the chamber instantly; (d) water transport and drip loss occurred in the duck carcass; and (e) drip loss and fat loss released from the hair follicles and chapped areas on the surface of the carcasses were immediately discharged out from the drainage hole at the bottom of the chamber rapidly.

\subsubsection{Instrumental Measurement of Water Activity and Surface}

The water activity of the skin samples (approximately $3 \mathrm{~g}$ ) was determined using a water activity meter (LabSwift-aw, Novasina, Lachen, Switzerland). The colour of the duck breast skin was measured with a Minolta chromameter (model, CR-200, Konica Minolta Sensing, Inc., Osaka, Japan). Lightness $\left(L^{*}\right)$, redness $\left(a^{*}\right)$ and yellowness $\left(b^{*}\right)$ were recorded in triplicate on non-overlapping areas of the skin surface and values were then averaged. The temperature on the duck breast skin surface was monitored with an infrared thermometer (Raytek Minitemp FS, Raytek Corp., Santacruz, CA, USA).

\subsubsection{The BaP and Heterocyclic Aromatic Amines Determination}

Analysis of 3,4-benzo(a)pyrene Content

In the present study separation and quantification of 3,4-benzo(a)pyrene (BaP) was performed using ultra-performance liquid chromatography with diode array and fluorescence detection (UPLC-DAD/FLD) (NY/T 1666-2008, China). Briefly, $5 \mathrm{~g}$ of ground duck skin samples was extracted three times with $45 \mathrm{~mL}$ cyclohexane in an ultrasound bath for $27 \mathrm{~min}$. The extract was concentrated nearly to $1 \mathrm{~mL}$ in a rotavapour at $40^{\circ} \mathrm{C}$. Then, the concentrate was extracted two times with $10 \mathrm{~mL}$ dimethyl sulfoxide for $8 \mathrm{~min}$. The mixture of the resulting extract and $15 \mathrm{~mL}$ of $2.0 \mathrm{~g} / \mathrm{L}$ sodium sulphate solution was extracted three times with $15 \mathrm{~mL}$ cyclohexane for $12 \mathrm{~min}$. The eluate was concentrated nearly to dryness under a stream of nitrogen gas and then diluted to $1.0 \mathrm{~mL}$ with formaldehyde for use of analysis of 3,4-benzo(a)pyrene. A UPLC unit (Agilent, Santa Clara, CA, USA) was equipped with a G4220B pump and G4226A autosampler with a $10 \mathrm{~mL}$ loop. A G1321B fluorescence detector was used 
for the detection of BaP. The column used was a ZORBA X Eclipse Plus C18 column $(2.1 \times 100 \mathrm{~mm}$, $1.8 \mu \mathrm{m}$ ) and the temperature of the column was held at $30^{\circ} \mathrm{C}$. Acetonitrile (A) and water (B) were used for the mobile phase at a flow rate $0.64 \mathrm{~mL} / \mathrm{min}$. The linear gradient was as follows: $0-2 \mathrm{~min}$, 50\% A; 2-8 $\mathrm{min}, 50-100 \%$ A; 8-11.2 $\mathrm{min}, 100 \% \mathrm{~A}$; and $11.2-15 \mathrm{~min} 100-50 \%$ A. The retention time for the analyte was $9.26 \mathrm{~min}$. The injection volume was $4 \mathrm{uL}$. The standard for BaP was prepared by dissolving $5 \mathrm{mg}$ of each chemical in $50 \mathrm{~mL}$ of methanol. The concentrations of the BaP standard were 10, 100 and $200 \mathrm{ng} / \mathrm{mL}$. The detection wavelength was $230 \mathrm{~nm}$. The limit of detection (LOD) was $0.04 \mu \mathrm{g} / \mathrm{kg}$. A quantitative determination was performed using an external calibration curve.

\section{Analysis of Heterocyclic Aromatic Amines Content}

The HCAs were determined using the method developed by Yao et al. [11]. Briefly, $2 \mathrm{~g}$ of ground duck skin sample was used for the extraction and purification of HCAs. After solid-phase extraction, the samples were analysed using high-performance liquid chromatography (HPLC) coupled with an ultraviolet detector (UV) and a fluorescence detector was used. The determination and quantification were performed according to the method described by Yao et al. [11]. Separation was performed on a reverse-phase TSK gel ODS-80 TM column $(25 \mathrm{~cm} \times 4.6 \mathrm{~mm}, 5 \mu \mathrm{m})$ and the column temperature was $30^{\circ} \mathrm{C}$. The flow rate was $1 \mathrm{~mL} / \mathrm{min}$. Mobile phase A consisted of $0.05 \mathrm{M}$ ammonium acetate ( $\mathrm{pH}$ 3.2) using formic acid and mobile phase B was $100 \%$ acetonitrile. The linear gradient profile started with $95 \% \mathrm{~A}$ and $5 \% \mathrm{~B}$ and changed to 55\% A and $45 \% \mathrm{~B}$ after $25 \mathrm{~min}$ and back to the initial ratio after $35 \mathrm{~min}$ to equilibrate the column before the next injection. The retention time for the IQ, MeIQ, MeIQx, 4,8-DiMeIQx, 7,8-DiMeIQx, Norharman, Harman, PhIP, TrP1, TrP2 and MeA $\alpha \mathrm{C}$ were 7.673, $8.506,9.648,10.325,12.023,13.004,14.760,16.674,17.427,18.052,22.872$ and 24.62 min, respectively. The quantity of each individual HCA was determined according to standard calibration curves, which were established by standard solutions of each HCA at 0.5, 5 and $50 \mathrm{ng} / \mathrm{mL}$ for each compound. The range for the linearity study was $0.1-10 \mathrm{ng} / \mathrm{mL}$ for norharman, harman, Trp-P-2, Trp-P-1, PhIP, $\mathrm{A} \alpha \mathrm{C}$ and $\mathrm{MeA} \alpha \mathrm{C}$ and in the case of IQ, MeIQ, MeIQx, 7,8-DiMeIQx and 4,8-DiMeIQx, the range for the linearity was $10-1000 \mathrm{ng} / \mathrm{mL}$ and correlation coefficients for the various types of HCAs were $>0.999$. The limit of detection and limit of quantification of HCAs were estimated based on the peak-to-peak noise magnitude near analyte peaks with a known concentration and signal-to-noise ratio of 3:1 and 3:10, respectively.

\subsubsection{Statistical Analysis}

The experiments were performed in triplicate. Data were expressed as the mean \pm standard deviation. Analysis of variance (ANOVA) and Duncan's multiple range tests were performed using SAS version 9.2. $p<0.05$ was considered statistically significant.

\section{Result and Discussion}

\subsection{Effects of Drying Time on the Surface and Internal Temperatures of Ducks}

Duck carcasses were placed in the chamber in which the working temperature reached $130{ }^{\circ} \mathrm{C}$. As shown in Figure 1, the surface temperature of ducks increased with time, reaching $80{ }^{\circ} \mathrm{C}$ at $40 \mathrm{~min}$ of drying, and then increased rapidly until reaching $110.9^{\circ} \mathrm{C}$ at $70 \mathrm{~min}$ of drying. There was no significant difference in the surface temperature between 70 and 90 min of drying $(p>0.05)$. In fact, the surface temperature reached a maximum plateau. However, at the same time, the internal temperature of duck carcasses increased significantly at different times during the drying process $(p<0.05)$, reaching $55.4,65.9,77.4,80.5$ and $83.7^{\circ} \mathrm{C}$ at $40,50,70,80$ and $90 \mathrm{~min}$ of drying, respectively. The difference between the surface temperature and internal temperature was approximately $30{ }^{\circ} \mathrm{C}$ after $60 \mathrm{~min}$ of drying, and this difference remained stable until the drying time was $90 \mathrm{~min}$. A similar pattern of temperature changes was observed in a prior study involving the roasting of pork, Longissimus dorsi [3]. This previous study reported that in a convection oven, the centre temperature was far below 
the surface temperature observed from the measured temperature profiles. In another recent study [2], investigators reported that in a numerical 3D model of coupled transport phenomena and texture changes during the roasting of chicken breast in a convection oven, the surface temperature was far higher than the measured core temperature for the different process settings.

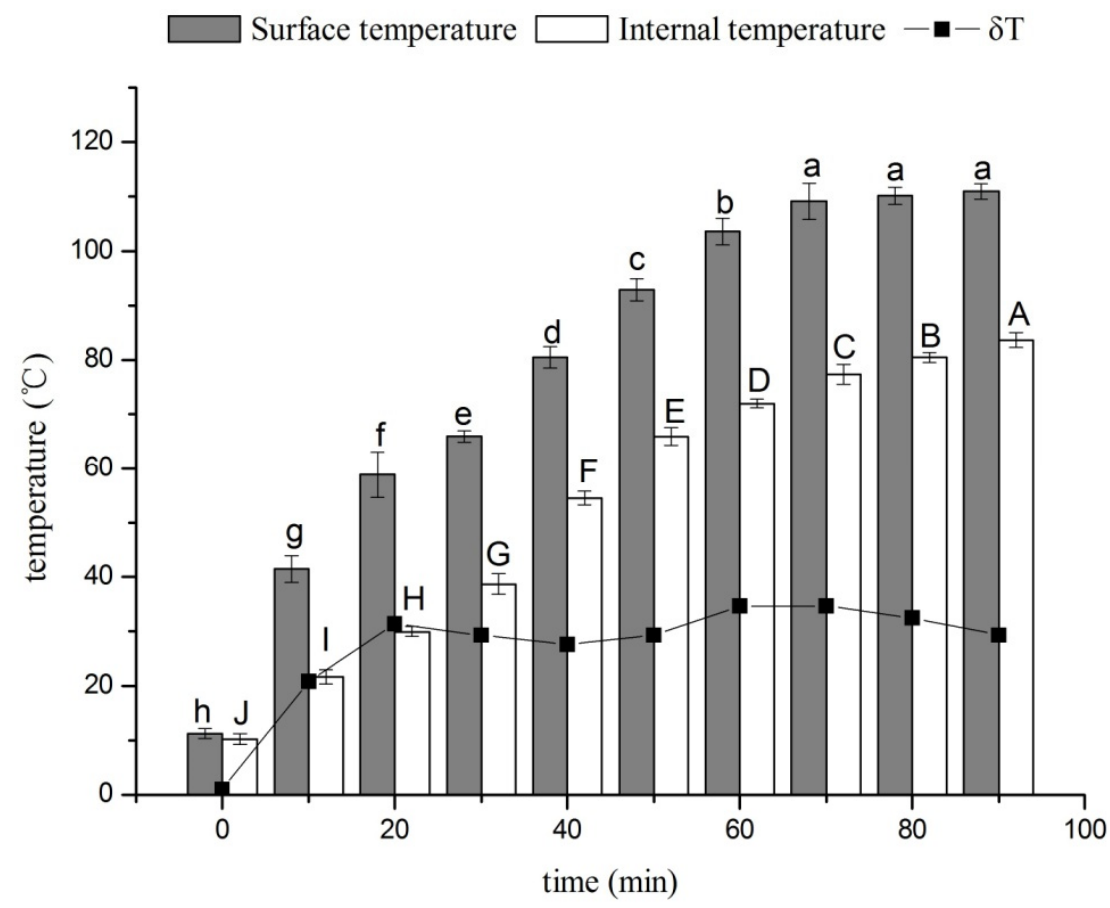

Figure 1. Variation of the surface temperature and internal temperature during drying. Note: Different uppercase/lowercase letters means differ significantly $(p<0.05)$.

\subsection{Coupling of Water Activity and $a^{*}$ of Roast Duck Skin under Simultaneous Heat and Mass Transfer}

The relationship between water content and water activity is indicated by a function known as the sorption isotherm of a food [18]. In this work, the water activity (in lieu of moisture content) was employed as an index to describe the effect of water content on the colour development of duck skin because the important determinants were temperature, time, composition of the system and water activity [19]. As shown in Figure 2, the water activity $\left(\mathrm{a}_{\mathrm{w}}\right)$ in the duck skin decreased slowly from 0 to $50 \mathrm{~min}$, and then declined sharply from 60 to 90 min of drying $(p<0.05)$. The changes in $\mathrm{a}_{\mathrm{w}}$ can be explained by changes in the surface temperature and internal temperature of ducks. The increased temperatures cause denaturation of duck protein in the skin, leading to a decrease in the water holding capacity. In particular, when the internal temperature is between 50 and $60{ }^{\circ} \mathrm{C}$, there is considerable moisture loss (approximately 30\%) as drip loss [20]. During the subsequent drying process, water was rapidly evaporated at the surface of the duck skin, and a dry layer that was impermeable to water could be formed on the surface of the skin. Thus, the water activity was in the $\mathrm{a}_{\mathrm{w}}$ range of 0.96-0.938, which is sufficiently low to be useful for Maillard browning [21]. Further, it was possible that a single moisture content value may correspond to several different water activity values under different temperatures [22].

Contrary to the changes in $\mathrm{a}_{\mathrm{w}}$, the red index $\left(\mathrm{a}^{*}\right)$ on the skin climbed drastically from 20 to $70 \mathrm{~min}$ $(p<0.05)$ and then became relatively stable. The $\mathrm{a}^{*}$ reached a plateau value (approximately 12.2) at 70 min of drying. As far as the manufacturer is concerned, the most significant and obvious effects of the Maillard reaction are the development of a golden brown colour or caramel aroma that develops during heating. In the present work, reducing sugars in the bee honey could react with either free amino groups or amino groups on proteins in the duck skin, readily resulting in colour formation on the duck skin surface. It is worth noting that the $a_{w}$ curve and $a^{*}$ curve intersect each other at 
50 min of drying, where a visible colour on the skin surface appeared. At 70 min of drying, the desired colour of roast duck formed. In other words, the red index $\left(\mathrm{a}^{*}\right)$ in the skin surface rose by $87.91 \%$ within the first hour of drying, whereas it increased by $12.09 \%$ within $30 \mathrm{~min}$ in the later stage of drying. An increase in temperature and/or time of heating resulted in increased colour development. At $50{ }^{\circ} \mathrm{C}$, the development of colour in the glucose and glycine model system increased with time [19]. Additionally, Labuza and Saltmarch [23] showed that the brown pigment produced in an aqueous mixture of glucose and glycine was proportional to the square of the reaction time. However, in practice, very little information is available about the water activity and colour development for processed meats during dry-heating conditions in a convection oven, except that the mathematical models of coupled heat and mass transfer during the roasting of meat in a convection oven have been developed [3]. Changes in water activity and temperature in a kinetic model for browning in the baking of biscuits have also been studied [24].

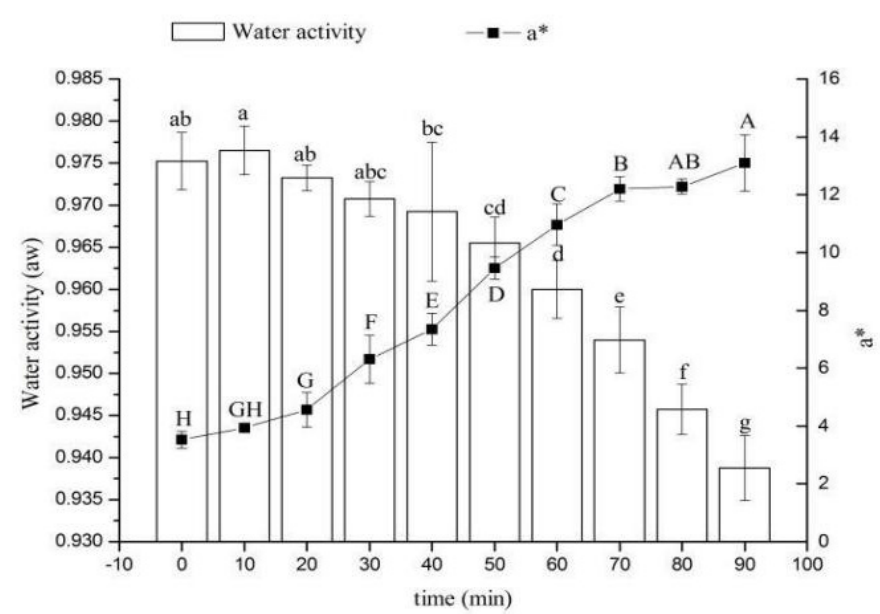

Figure 2. Variation of the water activity and a* during drying. Note: Different uppercase/lowercase letters means differ significantly $(p<0.05)$.

\subsection{Prediction of Finished Duck Skin Colour under Simultaneous Heat and Mass Transfer}

The values of $\mathrm{a}_{\mathrm{w}}$ of the skin declined by $40.5 \%$ in the first hour of drying, but decreased by $59.5 \%$ within $0.5 \mathrm{~h}$ in the later stage (Figure 3), whereas the surface temperature increased by $92.6 \%$ and $7.4 \%$ in the two stages, respectively. Moreover, the internal temperature increased by $84.2 \%$ and $15.8 \%$ in the two stages, respectively (Figure 1). The later stage of the drying process, thereby, is important for colour development on the skin surface. Apart from the $a^{*}$ curve, as shown in Figure 3 , the $a_{w}$ curve intersects the curve of the surface temperature at approximately $50 \mathrm{~min}$ of drying, and the curve of the internal temperature at $60 \mathrm{~min}$ of drying. It was revealed that the duck skin surface can show good colour development under these conditions inside the area surrounded by the $\mathrm{a}_{\mathrm{w}}$ curve and the internal temperature curve. The elementary colour formation on the surface was not completed until $70 \mathrm{~min}$ of drying. In the $\mathrm{a}_{\mathrm{w}}$ range of $0.96-0.938$, the drastic decline in $\mathrm{a}_{\mathrm{w}}$ makes the Maillard reaction occur immediately after the intersection of the surface temperature curve and $\mathrm{a}_{\mathrm{w}}$ curve. Consequently, the decreased water activity accelerates the browning course inside the duck skin at mild temperatures, particularly in the later stage of drying. In other words, the colour development on the duck skin surface is water activity-dependent. This is consistent with a previous finding that in a glucose-lysine-avicel model system held at $40{ }^{\circ} \mathrm{C}$, the browning rate decreased slightly from $\mathrm{a}_{\mathrm{w}}=0.4$ to 0.75 , with a rapidly greater decrease from $\mathrm{a}_{\mathrm{w}}=0.23$ to 0.4 [21]. In most cases, studies investigating both $\mathrm{a}_{\mathrm{w}}$ and temperature were not performed. Therefore, relatively little is known about the effects of water activity and temperature on the colour development of duck and chicken skin caused by drying, roasting or grilling, except for contradictory results. In contrast to the present work, Labuza and Saltmarch [23] showed that in dried anchovy held at $20^{\circ} \mathrm{C}$ for two months at $\mathrm{a}_{\mathrm{w}}$ ranging from 
0.11 to 0.93 , the maximum browning rate took place at $\mathrm{a}_{\mathrm{w}}=0.93$. Mundt and Wedzicha [24] found that in a kinetic model for browning in the baking of biscuits, the rate of browning for biscuit dough samples was independent of $\mathrm{a}_{\mathrm{w}}$ under the conditions investigated. Browning on the glycosylation of $\beta$-lactoglobulin with dextran under the dry-heating conditions occurred faster during the reaction at the highest $a_{w}$ [25]. In the present work, however, before the intersection of the $a^{*}$ curve and $a_{w}$ curve, there was no visible colour in spite of $\mathrm{a}^{*}$, thus suggesting that the colour development of the duck skin surface may be dependent on $\mathrm{a}_{\mathrm{w}}$ but not drying time. In addition, the unique flavour of roasted duck is associated with the development of colour.

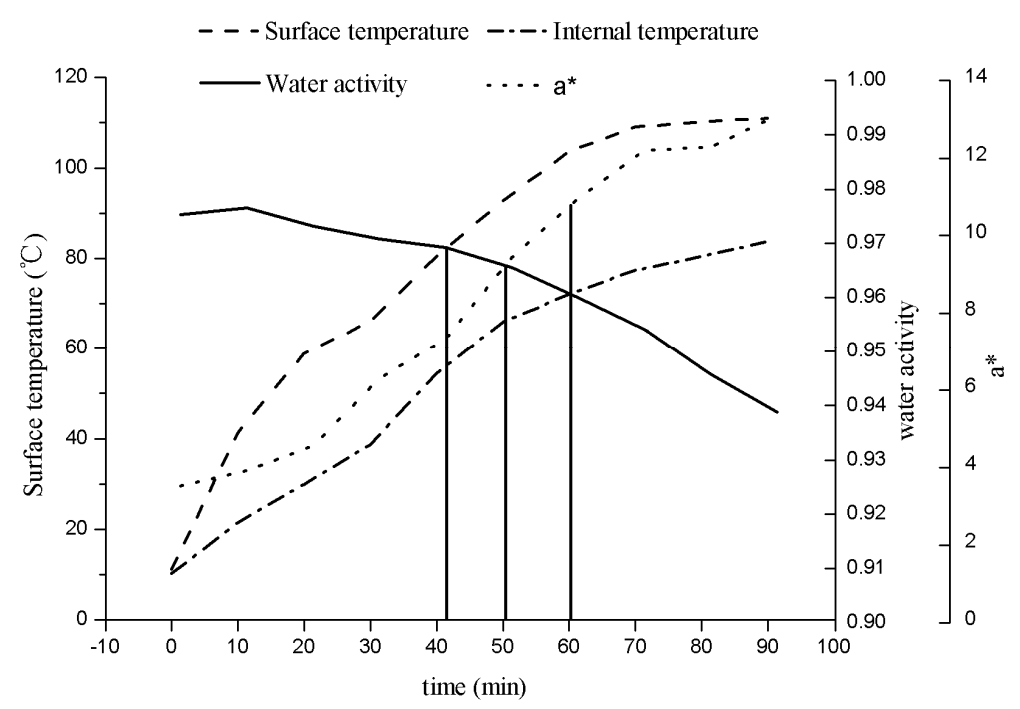

Figure 3. Alteration of the temperatures, water activity and red colour during drying.

In summary, under the conditions of $\mathrm{a}_{\mathrm{w}}$ in the range of $0.964-0.938$, surface temperature in the range of $109^{\circ} \mathrm{C}-111.9^{\circ} \mathrm{C}$ and internal temperature in the range of $77^{\circ} \mathrm{C}-83.7^{\circ} \mathrm{C}$, an expected $\mathrm{a}^{*}$ and a desired colour of the finished roast duck can be obtained.

\subsection{BaP and Heterocyclic Aromatic Amine Contents in Hot-Air Drying Ducks}

The UHPLC analysis showed that 3,4-benzo(a)pyrene was not detected in hot-air drying samples (Table 1). However, in Peking duck A, the highest level of BaP was $2.94 \mu \mathrm{g} / \mathrm{kg}$, and this content did not exceed the Chinese National Criteria [17] (less than $5 \mu \mathrm{g} / \mathrm{kg}$, GB7104-1994), but violated the regulation [16] that the content of $\mathrm{BaP}$ in processed cereal-based foods should not exceed $1.0 \mu \mathrm{g} / \mathrm{kg}$ (the legal proposed limits by the Official Journal of the European Union). In the present work, the large difference in $\mathrm{BaP}$ content of roast ducks between supermarkets is in accordance with a recent study in Peking duck [8], which found that levels of 3,4-benzo(a)pyrene reached $8.7 \mu \mathrm{g} / \mathrm{kg}$ in the duck skin in an open wood burning fire, and less than $1 \mu \mathrm{g} / \mathrm{kg}$ in both a closed oven procedure and electric heating. The PAH profile and levels are affected by various cooking factors, especially roasting temperature and duration [26]. The high level of 3,4-benzo(a)pyrene in the duck skin in an open wood burning fire may be related to the unsaturated hydrocarbons in the subcutaneous duck fat dripping on used wood because of the incomplete combustion or pyrolysis of the subcutaneous fat. Fortunately, 3,4-benzo(a)pyrene was not detected in the present work.

Eight of twelve HCAs in duck skin were detected in all of the samples (Table 2). The present study focused on the content of HCAs, and the limits of detection were as follows: $2.45 \mathrm{ng} / \mathrm{g}$ for IQ, $1.94 \mathrm{ng} / \mathrm{g}$ for MeIQ, $1.4 \mathrm{ng} / \mathrm{g}$ for MeIQx, $0.97 \mathrm{ng} / \mathrm{g}$ for 4,8-DiMeIQx, $0.95 \mathrm{ng} / \mathrm{g}$ for 7,8-DiMeIQx, $0.1 \mathrm{ng} / \mathrm{g}$ for Norharman, $0.07 \mathrm{ng} / \mathrm{g}$ for Harman, $0.06 \mathrm{ng} / \mathrm{g}$ for Trp-P-2, $0.04 \mathrm{ng} / \mathrm{g}$ for PhIP, $0.03 \mathrm{ng} / \mathrm{g}$ for Trp-P-1, $0.05 \mathrm{ng} / \mathrm{g}$ for $\mathrm{A} \alpha \mathrm{C}$ and $0.01 \mathrm{ng} / \mathrm{g}$ for MeA $\alpha \mathrm{C}$. The HPLC analysis revealed that Norharman and Harman were detected in all of the samples, whereas MeIQx and PhIP were detected in samples of 
company A; 4,8-DiMeIQx and Trp-P-2 in samples of company B; and IQ, 4,8-DiMeIQx, Trp-P-2, PhIP and $\mathrm{A} \alpha \mathrm{C}$ in samples of company $\mathrm{C}$. For Norharman and Harman, the present result is in line with the findings of Yao et al. [11], showing that Norharman and Harman were detected in all chicken skin samples after deep frying. In the same study, Norharman was the most abundant HCA, followed by Harman. The International Agency for Research on Cancer (IARC) classified IQ as a probable human carcinogen (class 2A), and MeIQ, MeIQx, PhIP, Trp-P-2 and A $\alpha \mathrm{C}$ as possible human carcinogens (class 2B). Thus, the effect of roast ducks on the daily intake of HCAs should not be overlooked. IQ, MeIQ, MeIQx, PhIP, Trp-P-2 and A $\alpha \mathrm{C}$ were not detected in the present work. The formation of benzo(a)pyrene and heterocyclic amines is dependent on various factors such as cooking method, cooking time, cooking temperature, fat content and water content in raw ducks in spite of contradictory reports [12,27]. The potential reasons for this may be related to the mild thermal treatment of the duck and to the prevention of the drip and melted fat from dripping onto the heat source when using hot-air drying.

Table 1. The contents of $\mathrm{BaP}$ in breast skin samples from supermarkets $(\mu \mathrm{g} / \mathrm{kg}, n=3)$.

\begin{tabular}{|c|c|c|c|c|c|c|c|c|c|c|c|}
\hline \multicolumn{2}{|c|}{ Samples } & \multirow{2}{*}{$\begin{array}{c}\text { Contents } \\
0.81 \pm 0.1\end{array}$} & \multicolumn{2}{|c|}{ Samples } & \multirow{2}{*}{$\begin{array}{c}\text { Contents } \\
\text { ND } \\
0.91 \pm 0.1\end{array}$} & \multicolumn{2}{|c|}{ Samples } & \multirow{2}{*}{$\begin{array}{c}\text { Contents } \\
0.16 \pm 0.02 \\
\text { ND }\end{array}$} & \multicolumn{2}{|c|}{ Samples } & $\frac{\text { Contents }}{\text { ND }}$ \\
\hline $\begin{array}{c}\text { OWBF } \\
A^{*}\end{array}$ & $\begin{array}{l}1 \\
2 \\
3\end{array}$ & & $\begin{array}{c}\text { OWB } \\
\mathrm{B}^{*}\end{array}$ & $\begin{array}{l}1 \\
2 \\
3\end{array}$ & & $\begin{array}{l}\text { OGF } \\
C^{*}\end{array}$ & $\begin{array}{l}1 \\
2 \\
3\end{array}$ & & $\begin{array}{l}\text { HAD } \\
D^{*}\end{array}$ & $\begin{array}{l}1 \\
2 \\
3\end{array}$ & $\begin{array}{l}\text { ND } \\
\text { ND } \\
\text { ND }\end{array}$ \\
\hline
\end{tabular}

Note: OWBF, open wood burning fire; OGF, open gas flame; HAD, hot-air drying. ND = not detected. *: Samples A and B, Peking ducks of company A and B in Beijing, respectively; Sample C, roast duck of company C in Nanjing; Sample D, hot-air drying Samples.

Table 2. The contents of HCAs in duck breast skin samples from supermarkets $(\mathrm{ng} / \mathrm{g}, n=3)$.

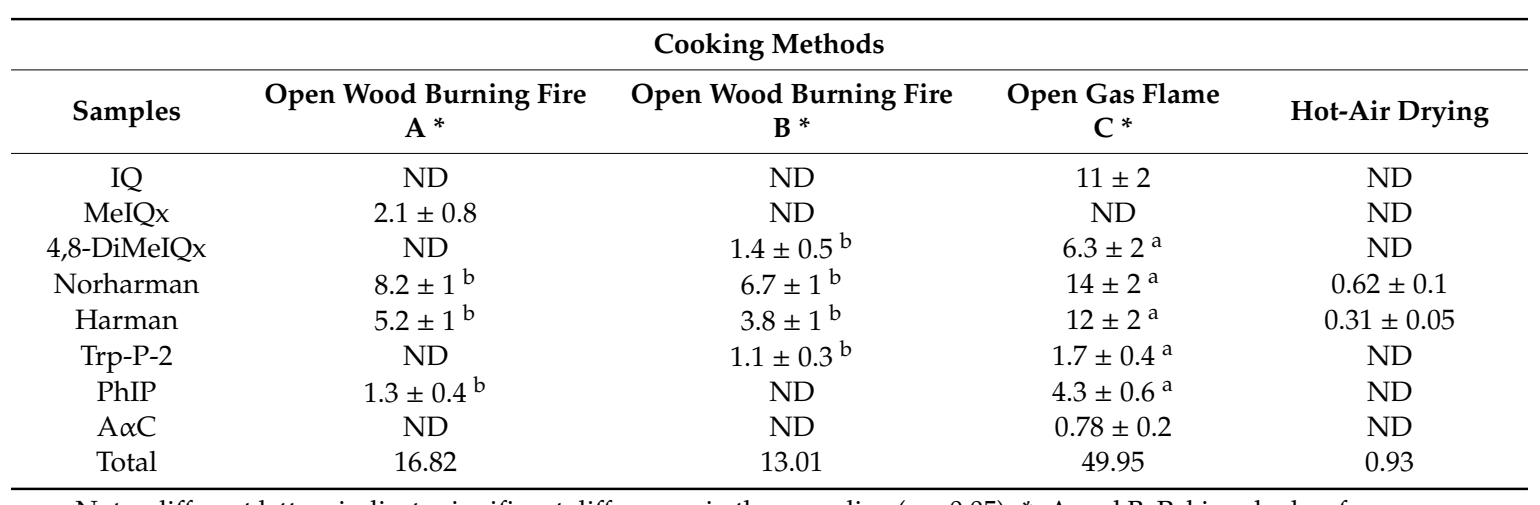

Note: different letters indicate significant differences in the same line $(p<0.05) . *$ : A and B, Peking ducks of company A and B in Beijing, respectively; C, roast duck of company C in Nanjing. Different lowercase letters in a row means differ significantly $(p<0.05)$.

\section{Conclusions}

Alterations of surface and internal temperatures, water activity and red index during mild cooking under forced hot-air convection evolved into an area of the finished roast duck that changed in colour and flavour. Water activity could be a better indicator for the redness on the skin surface of roast duck under the forced convection drying process. Meanwhile, the formation of HCAs and BaP effectively decreased. The hot-air drying technology developed in this study could be employed in place of roasting, grilling or barbecuing. Further research is warranted to investigate the law governing this process at temperatures below $130^{\circ} \mathrm{C}$, for example, $120^{\circ} \mathrm{C}$, for getting a delicious product with a lower content of harmful substances. At the same time, flavour development and the formation of volatile aroma components under forced convection drying need to be examined in future work. 
Author Contributions: Investigation, Y.P.; data curation, X.G. and Y.Z.; methodology, M.A.J.; project administration, Y.Z. All authors have read and agreed to the published version of the manuscript.

Funding: This research was funded by the China National Key R\&D Program during the 13th Five-year Plan Period (2018YFD0502306).

Conflicts of Interest: No conflict of interest existed in the submission of this paper.

\section{References}

1. Chen, B.H.; Lin, Y.S. Formation of Polycyclic Aromatic Hydrocarbons during Processingof Duck Meat. J. Agric. Food Chem. 1997, 45, 1394-1403. [CrossRef]

2. Felix, R.; Hailu, F.A. Modelling the transport phenomena and texture changes of chicken breast meat during the roasting in a convective oven. J. Food Eng. 2018, 237, 60-68.

3. Feyissa, A.H.; Gernaey, K.V.; Adler-Nissen, J. 3D modelling of coupled mass and heat transfer of a convection-oven roasting process. Meat Sci. 2013, 93, 810-820. [CrossRef]

4. Knize, M.G.; Felton, J.S. Formation and human risk of carcinogenic heterocyclic amines formed from natural precursors in meat. Nutr. Rev. 2005, 63, 158-165. [CrossRef] [PubMed]

5. IARC, International Agency for Research on Cancer. Monographs on the Evaluation of Carcinogenic Risks to Humans: Some Non-Heterocyclic Polycyclic Aromatic Hydrocarbons and Some Related Exposures; IARC: Lyon, France, 2010; Volume 92, pp. 1-868.

6. Skog, K.I.; Johansson, M.A.E.; Jägerstad, M.I. Carcinogenic heterocyclic amines in model systems and cooked foods: A review on formation, occurrence and intake. Food Chem. Toxicol. 1998, 36, 879-896. [CrossRef]

7. Matsumoto, T.; Yoshida, D.; Tomita, H. Determination of mutagens, amino-alpha-carbolines in grilled foods and cigarette smoke condensate. Cancer Lett. 1981, 12, 105-110. [CrossRef]

8. Lin, G.F.; Weigel, S.; Tang, B. The occurrence of polycyclic aromatic hydrocarbons in Peking duck: Relevance to food safety assessment. Food Chem. 2011, 129, 524-527. [CrossRef]

9. Chung, S.Y.; Yettella, R.R.; Kim, J.S. Effects of grilling and roasting on the levels of polycyclic aromatic hydrocarbons in beef and pork. Food Chem. 2011, 129, 1420-1426. [CrossRef]

10. Aaslyng, M.D.; Duedahl-Olesen, L.; Jensen, K. Content of heterocyclic amines and polycyclic aromatic hydrocarbons in pork, beef and chicken barbecued at home by Danish consumers. Meat Sci. 2013, 93, 85-91. [CrossRef]

11. Yao, Y.; Peng, Z.Q.; Shao, B. Effects of frying and boiling on the formation of heterocyclic amines in braised chicken. Poult. Sci. 2013, 92, 3017-3025. [CrossRef]

12. Rahman, U.U.; Sahar, A.; Khan, M.I. Production of heterocyclic aromatic amines in meat: Chemistry, health risks and inhibition. A review. LWT-Food Sci. Technol. 2014, 59, 229-233. [CrossRef]

13. Bouvard, V.; Loomis, D.; Guyton, K. Carcinogenicity of consumption of red and processed meat. Lancet Oncol. 2015, 16, 1599-1600. [CrossRef]

14. Lu, F.; Kuhnle, G.K.; Cheng, Q. Vegetable oil as fat replacer inhibits formation of heterocyclic amines and polycyclic aromatic hydrocarbons in reduced fat pork patties. Food Control 2017, 81, 113-125. [CrossRef]

15. Min, S.; Patra, J.K.; Shin, H.S. Factors influencing inhibition of eight polycyclic aromatic hydrocarbons in heated meat model system. Food Chem. 2018, 239, 993-1000. [CrossRef]

16. European Commission (EC). Council Regulation (EC) 835/2011/EC of 19 August 2011 amending Regulation (EC) No 1881/2006 as regards maximum levels for polycyclic aromatic hydrocarbons in foodstuffs. Off. J. Eur. Union 2011, L215, 4-8.

17. Tolerance Limit of Benzo(a)pyrene in Foods, GB7104-1994. Available online: http://www.bzywb.com/ bzdetail/487/E8E66E06.shtml (accessed on 10 September 2020).

18. Belitz, H.D.; Grosch, W.; Schieberle, P. Food Chemistry, 4th ed.; Springer: Berlin/Heidelberg, Germany, 2009; pp. 3-5.

19. Ames, J.M. Control of the Maillard reaction in food systems. Trends Food Sci. Technol. 1990, 1, 150-154. [CrossRef]

20. Warriss, P.D.; Ebrary, I. Meat science: An introductory text. Int. J. Food Sci. Technol. 1999, 36, 439-449.

21. Lewicki, P.P.; Arboix, J.A.; Boto, P.G.; Beringues, J.C.; Moreno, I.M. Drying. In Encyclopedia of Meat Sciences, 2nd ed.; Academic Press: Cambridge, MA, USA, 2014; pp. 471-479. 
22. Enriqueza, E.J.; Olivasa, G.I.; Ortega-Rivasb, E.; Zamudio-Floresa, P.B.; Perez-Vegab, S.; Sepulveda, D.R. Water activity, not moisture content, explains the influence of water on powder flowability. LWT-Food Sci. Technol. 2019, 100, 35-39.

23. Labuza, T.P.; Saltmarch, M. The nonenzymatic browning reaction as affected by water in foods [Shelf life of food products]. Water Act. Influ. Food Qual. 1981, 605-650.

24. Mundt, S.; Wedzicha, B.L. A kinetic model for browning in the baking of biscuits: Effects of water activity and temperature. LWT-Food Sci. Technol. 2007, 40, 1078-1082. [CrossRef]

25. Jiménez-Castanõ, L.; Villamiel, M.; Martıń-Álvarez, P.J. Effect of the dry-heating conditions on the glycosylation of $\beta$-lactoglobulin with dextran through the Maillard reaction. Food Hydrocoll. 2005, 19, 831-837. [CrossRef]

26. Singh, L.; Varshney, J.G.; Agarwal, T. Polycyclic aromatic hydrocarbons' formation and occurrence in processed food. Food Chem. 2016, 199, 768-781. [CrossRef] [PubMed]

27. Alomirah, H.; Al-Zenki, S.; Al-Hooti, S. Concentrations and dietary exposure to polycyclic aromatic hydrocarbons (PAHs) from grilled and smoked foods. Food Control 2011, 22, 2028-2035. [CrossRef]

(C) 2020 by the authors. Licensee MDPI, Basel, Switzerland. This article is an open access article distributed under the terms and conditions of the Creative Commons Attribution (CC BY) license (http://creativecommons.org/licenses/by/4.0/). 